\title{
Envelhecimento UV de ligantes asfálticos
}

\author{
L. S. da Silva e M. M. C. Forte \\ Departamento de Materiais, Escola de Engenharia, \\ Universidade Federal do Rio Grande do Sul, Porto Alegre, RS, Brasil
}

\author{
P. Bartolomeo, F. Farcas e F. Durrieu \\ Service de Physico Chimie des Matériaux, Laboratoire Central des Ponts et Chaussées, Paris, França
}

RESUMO: A deterioração de um pavimento está relacionada com o envelhecimento do ligante asfáltico. A radiação solar UV é um importante iniciador de reações que ocorrem na superfície do ligante asfáltico, formando uma camada oxidada e quebradiça. O método de simulação clássica de envelhecimento (RTFOT + PAV) em laboratório não leva em consideração o efeito da radiação UV. Com o objetivo de avaliar a influência da radiação UV no envelhecimento de ligantes asfálticos, sessões de exposição a radiação UV foram intercaladas entre os ensaios de simulação clássica. Dois ligantes asfálticos, quimicamente distintos, foram envelhecidos e avaliados, segundo sua composição química e estrutural, antes e após cada etapa da simulação de envelhecimento. A seqüência de ensaios proposta para simulação e avaliação do envelhecimento de ligantes asfálticos sob radiação UV mostrou-se altamente satisfatória. Os ligantes apresentaram mecanismos de envelhecimento distintos, tanto através de simulação clássica quanto através de exposição à radiação UV. A presença de vanádio na composição química dos ligantes foi determinante no envelhecimento sob radiação UV, comportando-se como um fotocatalisador na formação de aglomerados de macromoléculas na superfície do material.

\begin{abstract}
The asphalt pavement deterioration is related to the asphalt binder ageing. The UV radiation is an important agent for reactions that occur in the binder surface producing a fragile thin layer on it. The classic method for asphalt ageing simulation does not take in consideration the UV effect. The aim of this work was to evaluate the UV effect in the asphalt binder ageing. One new experimental test was introduced to those ones used in the classic ageing simulation (RTFOT + PAV), taking account the binder exposition to the UV radiation. Two asphalt binders were valuated by the classic simulation and by that one proposed in this work. The experimental tests sequence proposed in this work for simulation and evaluation of the binders ageing under UV radiation exposition was very successful. These binders before and after ageing had their chemical composition and structure determined. Both binders showed quite different ageing behavior in the presence or not of UV radiation. The presence of vanadium in these had a strong influence on the binder ageing, being a photocatalyst for the UV radiation producing agglomerates of macromolecules in the material surface.
\end{abstract}

\section{INTRODUÇÃO}

O ligante asfáltico utilizado em pavimentação pode se oxidar devido a vários fatores, tais como a presença de oxigênio, exposição à radiação ultravioleta e variações de temperatura (Herrington e Ball, 1996). Assim, durante a sua vida útil, o ligante asfáltico torna-se mais rígido e quebradiço, o que leva a formação de fissuras e degradação do pavimento. O processo de degradação do ligante asfáltico é chamado de envelhecimento.

O envelhecimento do ligante asfáltico é explicado por quatro processos: oxidação, endurecimento exsudativo, endurecimento físico e perda de voláteis (Whiteoak, 1990). Dentre esses, a oxidação é o mais significativo: ocorre principalmente durante a aplicação do revestimento asfáltico e continua, de forma mais lenta, durante seu uso. Embora a estocagem do ligante asfáltico se faça a altas temperaturas, a oxidação nos tanques é restrita à superfície que está exposta ao ar. Além da formação de compostos oxigenados, os grupos polares já presentes no ligante asfáltico tendem a se associar, formando micelas e aglomerados de alto peso molecular e maior viscosidade, chamados de asfaltenos. Dentre os fatores que influenciam estas reações e reestruturações do ligante asfáltico, destacam-se a temperatura máxima no verão, as interações com os agregados e o teor de vazios do pavimento. O endurecimento exsudativo é resultante da migração de componentes oleosos do ligante para o agregado mineral. $\mathrm{O}$ endurecimento físico, fenômeno reversível que acontece a temperatura 
ambiente, é atribuído à reordenação de moléculas e à cristalização de parafinas da fração saturada do ligante asfáltico. A perda de voláteis no ligante asfáltico é baixa e considerada de pouca importância no processo de envelhecimento (Barth, 1962).

Segundo alguns pesquisadores (Knoterus, 1973; Glita, 1988), outro fator relevante no envelhecimento do ligante asfáltico é a radiação ultravioleta (UV). A radiação solar atinge a superfície do pavimento e desencadeia reações radicalares in situ, servindo-se de substratos presentes no ligante asfáltico para formar rapidamente uma camada superficial altamente oxidada. Durante a amostragem de ligantes asfálticos envelhecidos, deve-se considerar toda a massa da amostra, i.e., a camada superior exposta aos raios UV e a camada inferior, de maneira que o resultado corresponderá a um valor médio da superfície e do ligante subjacente (Glita, 1988).

A susceptibilidade ao envelhecimento de um ligante asfáltico também depende da presença de certos metais em sua composição química. Estudos anteriores destacam que ligantes asfálticos susceptíveis a oxidação, ou envelhecimento, apresentam entre outras características, traços de metais (Wright e Paquette, 1968; Traxler e Scrivner, 1971; Ishai, 1984; Knoterus, 1973; Glita, 1988). Traxler (1971) verificou a existência de uma relação entre o endurecimento do ligante asfáltico e o teor de vanádio neste; Green (citado por Ishai, 1984) atribuiu a este elemento poder catalítico no processo de foto-oxidação do asfalto. Glita (1988) observou que o vanádio pode ser um agente de agregação durante o envelhecimento do ligante asfáltico, pois está presente principalmente na fração de maior peso molecular, ou seja, nos asfaltenos. A análise do ligante após envelhecimento mostrou um aumento do teor de vanádio na fração asfalteno, o que indicaria uma migração dos agregados formados por moléculas menores e vanádio na porção oleosa para a porção asfaltênica.

O teor de níquel e vanádio num ligante asfáltico está relacionado à origem do petróleo bruto. Os ligantes asfálticos provenientes da Venezuela, por exemplo, possuem alto teor de vanádio e níquel; já aqueles provenientes da África Ocidental apresentam traços de vanádio e são ricos em níquel (Druon et al, 2000).

Em 1960, Mertens (Leite e Camillo, 1988) observou uma correlação linear entre o envelhecimento, em ensaios acelerados, e o teor de asfaltenos do ligante asfáltico. Sabe-se também que a incorporação de oxigênio no ligante asfáltico é bem mais rápida nos compostos que apresentam heteroátomos, podendo haver associações intra e intermoleculares por pontes de hidrogênio. Sendo assim, a formação de moléculas mais complexas e de maior massa molar pode também ser explicada por interações moleculares envolvendo compostos polares (Moschopedis, 1975).

Atualmente são utilizadas duas técnicas para simular o envelhecimento de ligantes asfálticos em laboratório. A primeira, Rolling Thin Film Oven Test (RTFOT) (ASTM D 2872-88) simula o envelhecimento do ligante asfáltico durante o processo de usinagem, que acontece na sua aplicação. Para isto, o ensaio é realizado sob altas temperaturas e em presença de oxigênio. A segunda técnica, Pressure Aging Vessel (PAV), foi desenvolvida pelo Strategic Highway Research Program (SHRP) para simular o envelhecimento do ligante asfáltico in situ, ou seja, durante a sua utilização como pavimento. Este ensaio é realizado sob alta pressão, baixa temperatura e longos tempos, podendo simular até décadas. O PAV é realizado no ligante asfáltico após o ensaio de RTFOT e a seqüência dos testes de envelhecimento RTFOT + PAV chama-se "envelhecimento clássico". Um ligante asfáltico submetido ao envelhecimento clássico apresenta as mesmas características de um ligante asfáltico com três a seis anos de uso, dependendo da sua composição, do agregado e da maneira como este foi aplicado no pavimento (Farcas, 1996; Migliori, 1998; Bahia et al, 2001). Segundo Migliori (1998), para que o ligante envelhecido apenas por PAV atinja estas mesmas características é necessário um tempo maior de ensaio.

Após a simulação, o ligante asfáltico envelhecido pode ser avaliado segundo várias técnicas de análise instrumental, desde aquelas mais simples, ditas clássicas, utilizadas para fins de especificação, até aquelas mais complexas, úteis na elucidação e entendimento do comportamento do ligante asfáltico. Os ensaios clássicos de caracterização e especificação de ligantes asfálticos consistem na determinação da penetração a $25^{\circ} \mathrm{C}$ (NF EN 1426), na determinação da temperatura de amolecimento anel e bola (NF EN 1427) e na determinação da viscosidade Brookfield (NF EN 12595). Outras análises utilizadas para uma caracterização mais completa do ligante asfáltico são: a cromatografia em coluna de sílica (IATROSCAN), que identifica e quantifica as suas frações químicas genéricas SARA (Saturados, Aromáticos, Resinas e Asfaltenos); a Cromatografia por Permeação em Gel "ultra-rápido" (GPC ultrarápido), que separa os compostos por massa molar; a espectroscopia de infravermelho (FTIR), que identifica os compostos formados na oxidação; e, finalmente, a Reometria de Cisalhamento Dinâmico (DSR), que permite observar as variações do comportamento viscoelástico do material envelhecido.

Os objetivos deste trabalho foram avaliar a influência da radiação UV no envelhecimento de ligantes 
asfálticos e verificar a influência da composição química destes no mecanismo de envelhecimento. Para tanto, buscou-se adequar um procedimento de análise para melhor avaliar o efeito da luz UV no envelhecimento do ligante asfáltico, identificando as técnicas mais apropriadas para tal, com avaliação deste em cada etapa do experimento quanto à composição química e estrutural. Foram estudados dois ligantes asfálticos de diferentes origens - portanto, com composição química diferente -, os quais foram submetidos ao "envelhecimento clássico" e ao "envelhecimento clássico mais exposição à luz UV".

\section{MATERIAIS E MÉTODOS}

\subsection{Matérias-primas e amostragem}

Foram utilizados dois ligantes asfálticos de origens diferentes, um proveniente de uma refinaria brasileira, identificado como BRA, e outro proveniente de uma refinaria francesa, identificado como FRA. O primeiro foi doado pela Ipiranga Asfaltos (Canoas/ $\mathrm{RS} / \mathrm{Br}$ ) e o segundo pelo Laboratoire Central des Ponts et Chaussées (LCPC/Paris/Fr).

Os ligantes asfálticos foram inicialmente aquecidos a $160^{\circ} \mathrm{C}$, por aproximadamente 20 minutos, tornando-se líquidos viscosos, sendo homogeneizados com auxílio de uma espátula de metal. Depois, foram moldados para obtenção de corpos de prova do tipo placa (espesso) ou pastilha (fino), dependendo do ensaio a ser realizado. Para preparação das placas, foram colocadas $12,5 \mathrm{~g}$ de ligante asfáltico fluído em placas com diâmetro de $14,0 \mathrm{~cm}$, a fim de se obter um filme de 2,0 $\mathrm{mm}$ de espessura. Para as amostras na forma de pastilha, espalhou-se, com auxílio de uma lâmina de vidro, uma gota de ligante asfáltico, sobre uma pastilha de CsI ou $\mathrm{NaCl}$. O filme resultante possuía em média $700 \mu \mathrm{m}$ de espessura.

\subsection{Simulação de envelhecimento}

\subsubsection{Simulação clássica}

A simulação clássica de envelhecimento consiste na seqüência dos ensaios RTFOT e PAV. No primeiro, um filme fino do ligante asfáltico, em rotação constante, foi exposto à temperatura de $165^{\circ} \mathrm{C}$ durante 75 minutos, em presença de oxigênio. Após este período, o material foi avaliado segundo sua variação de massa, penetração e ponto de amolecimento. Este teste, que simula o envelhecimento durante a usinagem, foi realizado de acordo com a norma européia NF EN 12607-1, baseada na norma americana ASTM D 2872-88. No ensaio de PAV, o ligante asfáltico foi colocado em um vaso sob pressão de 21,0 bars, durante $20 \mathrm{~h}$, a $100^{\circ} \mathrm{C}$. Este teste, que simula o envelhecimento em serviço, foi realizado de acordo com a norma americana SHRP/ AASHTO PP1. A seqüência de ensaios realizada está apresentada no Esquema 1. Após a simulação clássica, os ligantes foram caracterizados quanto a sua composição química e estrutura, em cada etapa de envelhecimento.

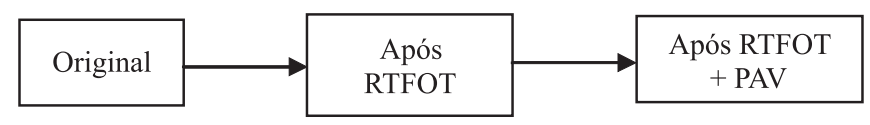

Esquema 1: Seqüência de ensaios da simulação clássica de envelhecimento

\subsubsection{Envelhecimento $U V$}

Este ensaio simula o envelhecimento do ligante asfáltico devido à incidência de radiação solar sobre o pavimento. O equipamento Atlas UV 2000, normalmente utilizado para ensaios de tintas, foi adaptado para os ensaios de ligantes asfálticos em placas, não existindo, portanto, uma norma técnica a ser seguida. Os ligantes asfálticos, após serem envelhecidos no ensaio RTFOT, foram expostos a radiação UV, com intensidade de $0,77 \mathrm{~W} / \mathrm{m}^{2}$, durante uma a cinco semanas, e depois foram submetidos ao ensaio PAV. A idéia de intercalar essas sessões de exposição à radiação UV aos ensaios já realizados, se deveu à suposição de que a radiação UV pode ter efeito iniciador nas reações que ocorrem durante o ensaio de PAV, que é feito sob condições mais severas. Como a temperatura dentro da câmara de simulação UV é de $60^{\circ} \mathrm{C}$, as amostras também foram expostas em estufa a esta temperatura, para fins de comparação de ambos efeitos. Assim a exposição dos ligantes à radiação UVA $\left(0,77 \mathrm{~W} / \mathrm{m}^{2}\right)$ a $60^{\circ} \mathrm{C}$, ou seja "UV $+60^{\circ} \mathrm{C}$ ", chamou-se por convenção "efeito UV", enquanto que, quando as amostras foram condicionadas na estufa somente com circulação de ar a $60^{\circ} \mathrm{C}$, chamou-se de "efeito T". A seqüência de envelhecimento então realizada está apresentada no Esquema 2.

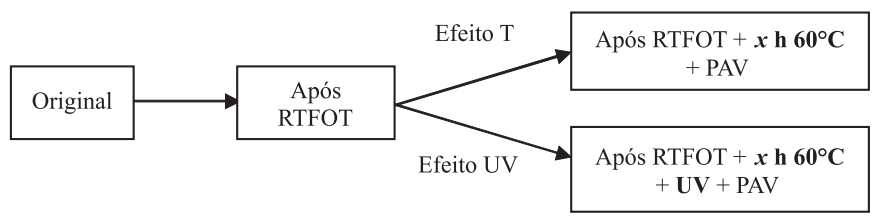

Esquema 2: Seqüência de ensaios da simulação de envelhecimento UV

As amostras foram expostas a radiação UV em placas contendo $2,0 \mathrm{~mm}$ de ligante asfáltico, avaliando-se o efeito UV na amostra global, uma vez 
que as análises foram realizadas na amostra homogeneizada após o envelhecimento. Após cada etapa do ensaio de envelhecimento proposto neste trabalho, os ligantes foram avaliados quanto a sua composição química e estrutura, como na simulação clássica.

\subsection{Caracterização dos ligantes asfálticos}

A penetração e o ponto de amolecimento dos ligantes asfálticos foram determinados, respectivamente, de acordo com as normas brasileiras MB-107 e MB-164 (ABNT, 1971 e 1972). Esses métodos são equivalentes aos descritos na Norma Francesa NF EN 12591 (Norma Européia, 1999).

A análise da composição química dos ligantes asfálticos foi realizada através de Espectrofotometria FTIR e Cromatografia em coluna de sílica (IATROSCAN). Os espectros de FTIR foram obtidos a partir do filme do ligante asfáltico (subseção 2.1) em um espectrofotômetro Nicolet (Impact 410) com 64 acumulações de leitura. O acompanhamento das modificações químicas através de FTIR pôde ser realizado pelo monitoramento das bandas referentes aos produtos formados durante a oxidação e também o desaparecimento de alguns grupamentos envolvidos nesta reação (Lamontagne, 2001; Durrieu, 2004). O uso de índices estruturais, calculados a partir da área da banda de interesse em relação à área total do espectro, tornou-se uma ferramenta útil na interpretação dos resultados, uma vez que minimizam os erros relativos ao ruído durante a aquisição do espectro e às variações de espessura do filme. As bandas monitoradas foram as de 1700, 1600, $1032 \mathrm{e}$ $800-740 \mathrm{~cm}^{-1}$, referentes respectivamente aos índices de oxidação $\left(\mathrm{I}_{\text {oxi }}\right)$, aromaticidade $\left(\mathrm{I}_{\text {aro }}\right)$, sulfóxido $\left(\mathrm{I}_{\mathrm{s}}\right)$ e de condensaçãa de aromáticos ( $\left.\mathrm{I}_{\text {cond }}\right)$ (Pieri, 1994).
A Figura 1 apresenta um espectro FTIR típico de um ligante asfáltico, as bandas dos grupos analisados e os índices calculados a partir destas.

A composição química genérica SARA (Saturados, Aromáticos, Resinas e Asfaltenos) dos ligantes asfálticos foi obtida a partir de uma solução asfáltica $\left(2 \%\right.$ em $\left.\mathrm{CHCl}_{3}\right)$ analisada em cromatógrafo IATROSCAN (MK-5 TLC/FID analyser). O percentual final destas quatro frações foi utilizado no cálculo do índice de instabilidade coloidal, ou Ic, que dá uma idéia da estabilidade do sistema coloidal asfáltico. Este índice é calculado pela expressão $\mathrm{Ic}=(\mathrm{S}+\mathrm{As}) /(\mathrm{R}+\mathrm{Ar})$, sendo que quanto maior o valor de Ic, mais instável é o meio.

A análise estrutural dos ligantes asfálticos foi realizada através de GPC ultra-rápido (Waters 515). Foram injetados $10 \mu \mathrm{L}$ de uma solução asfáltica (3\% em THF estabilizado) em uma coluna microStyragel de 500 Angströns, a uma vazão de $2,5 \mathrm{~mL} /$ min. Utilizaram-se dois detectores, um de refração (modelo 2410) e outro UV (modelo 440), no comprimento de onda de $340 \mathrm{~nm}$. A técnica recebe o nome de 'ultra-rápida' devido à alta vazão utilizada, que permite a visualização dos aglomerados de moléculas, sem sua dissociação. Os dados foram tratados em um software PL-DCU da Polymers Laboratoires e os cromatogramas resultantes sofreram deconvolução a fim de melhor comparar as frações segundo o tamanho das moléculas. Devido à complexidade do material e da interpretação destes resultados, estes foram expressos em termos de área relativa de cada gaussiana em relação à área total do cromatograma. Como o interesse deste estudo é o envelhecimento e este está associado diretamente à formação de compostos de maior massa molar, ou seja, à esquerda do cromatograma, reportou-se estes resultados em termos da área relativa da gaussiana 1, que também é chamado de pico de interação.

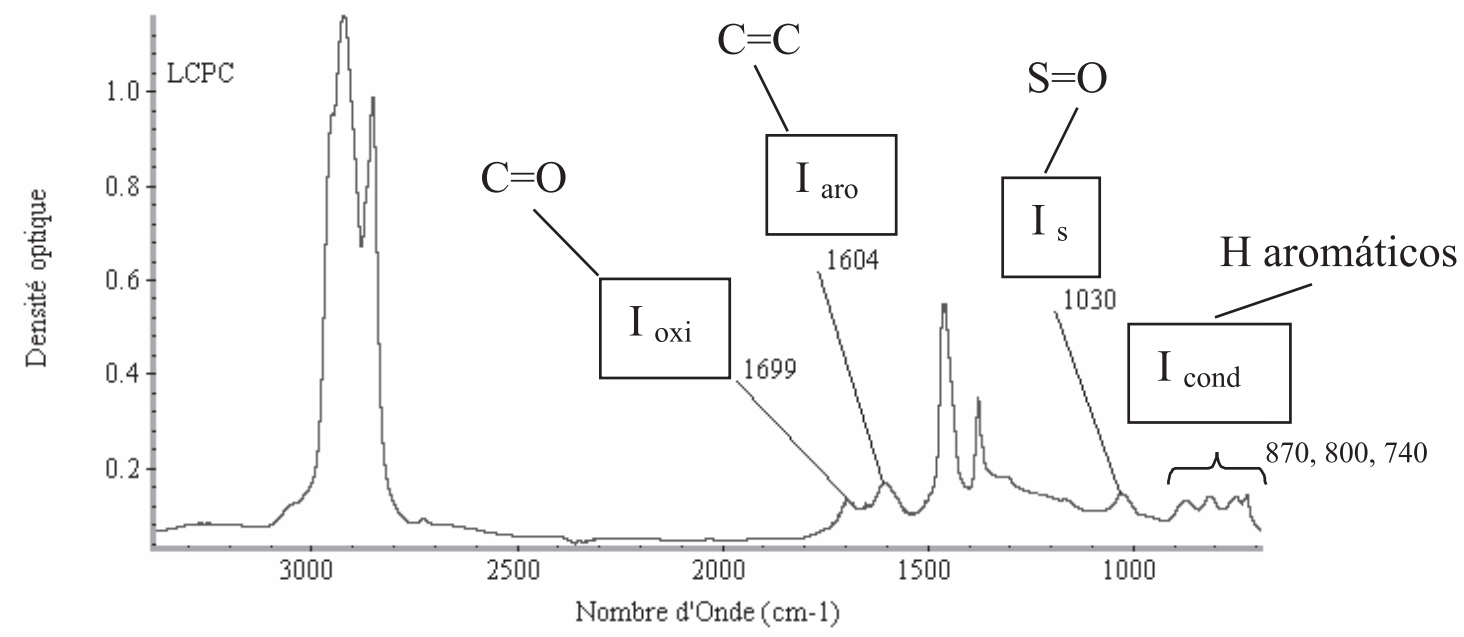

Figura 1: Espectro de FTIR típico de um ligante asfáltico e índices estruturais 
A análise reológica dos ligantes asfálticos foi realizada em um reômetro METRAVIB (VA 2000). Utilizou-se como geometria dos corpos de prova um cilindro de 9,0 $\mathrm{mm}$ de diâmetro e $18 \mathrm{~mm}$ de altura, para tração e compressão a baixas temperaturas (-30 a $30^{\circ} \mathrm{C}$ ), e um disco de $10 \mathrm{~mm}$ de diâmetro e $5 \mathrm{~mm}$ de altura, para cisalhamento a altas temperaturas ( $30 \mathrm{a}$ $80^{\circ} \mathrm{C}$ ). A cada temperatura foi realizada uma varredura de freqüência (1 a $200 \mathrm{~Hz}$ ) obtendo-se assim várias isotermas. Os resultados foram utilizados no cálculo do índice de Susceptibilidade termo-elástica $\left(\mathrm{E}_{\mathrm{T}}\right)$, que expressa a sensibilidade do módulo elástico $\mathrm{E}^{\prime}$ à temperatura. Este índice é dado pela razão entre os valores do módulo elástico E' a diferentes temperaturas e mesma freqüência, conforme exemplifica a equação: $\mathrm{E}^{\prime}{ }_{\mathrm{T}}=\mathrm{E}{ }^{\prime}\left(20^{\circ} \mathrm{C} ; 7,8 \mathrm{~Hz}\right) / \mathrm{E}^{\prime}\left(50^{\circ} \mathrm{C} ; 7,8 \mathrm{~Hz}\right)$ (Carreau et al, 2000).

\section{RESULTADOS E DISCUSSÕES}

\subsection{Comparação dos ligantes asfálticos após simulação clássica de envelhecimento (RTFOT + PAV)}

Antes de serem submetidos aos ensaios de envelhecimento, os ligantes asfálticos foram caracterizados através de ensaios clássicos, a fim de classificá-los quanto a sua especificação. A Tabela 1 apresenta os valores de Penetração (Pen) a $25^{\circ} \mathrm{C}$ e do Ponto de Amolecimento (PA) dos ligantes asfálticos FRA e BRA, antes e após ensaio RTFOT, bem como os limites aceitos pela Norma Européia NF EN 12591 (1999) com relação ao valor e variação do PA após RTFOT e da Pen residual (\%Pen res), calculada pela razão entre a Pen antes e após o ensaio de RTFOT.

Tabela 1: Propriedades clássicas dos ligantes asfálticos originais

\begin{tabular}{|l|c|c|c|c|}
\cline { 2 - 5 } \multicolumn{1}{c|}{} & \multicolumn{2}{c|}{ FRA } & \multicolumn{2}{c|}{ BRA } \\
\cline { 2 - 5 } \multicolumn{1}{c|}{} & Original & $\begin{array}{c}\text { Após } \\
\text { RFTOT }\end{array}$ & Original & $\begin{array}{c}\text { Após } \\
\text { RFTOT }\end{array}$ \\
\hline Pen $(1 / 10 \mathrm{~mm})$ & 42 & 29 & 53 & 34 \\
\hline $\begin{array}{l}\text { Pen res. }(\%) \\
\text { Limite }>53 \%\end{array}$ & \multicolumn{2}{|c|}{69} & \multicolumn{2}{|c|}{64} \\
\hline $\begin{array}{l}\text { PA }\left({ }^{\circ} \mathrm{C}\right) \\
\text { Limite após } \\
\text { RTFOT }>52,0^{\circ} \mathrm{C}\end{array}$ & 53,0 & 58,5 & 49,3 & 54,4 \\
\hline $\begin{array}{l}\Delta \text { PA }\left({ }^{\circ} \mathrm{C}\right) \\
\Delta_{\text {máx }}=8^{\circ} \mathrm{C}\end{array}$ & \multicolumn{2}{|c|}{5,5} & \multicolumn{2}{|c|}{5,1} \\
\hline
\end{tabular}

Segundo os resultados obtidos, ambos os ligantes asfálticos podem ser enquadrados na mesma especificação, seja esta brasileira (tipo CAP-20) ou européia (tipo 35/50). Mesmo que ambos ligantes asfálticos se enquadrem na mesma especificação, observa-se, segundo análise dos valores de Pen e PA, que o ligante FRA é levemente mais consistente que o ligante BRA, pois possui menor Pen e PA ligeiramente mais alto.

Classificar estes dois ligantes como sendo do mesmo tipo foi uma consideração necessária e um ponto de partida importante para prosseguir com análises mais detalhadas sobre seu envelhecimento. Sabe-se, portanto, que os ensaios de especificação são puramente físicos e que a durabilidade de ligantes asfálticos está intimamente relacionada com a sua composição química (Barth, 1962; Knoterus, 1973 e Glita, 1988).

\subsubsection{Análise FTIR}

Os gráficos da Figura 2 apresentam os valores dos índices estruturais, calculados a partir dos espectros de FTIR, ao longo das etapas de envelhecimento clássico. A formação de grupamentos carbonila durante o envelhecimento, representada pelo $\mathrm{I}_{\text {oxi}}$, ocorre apenas no ligante BRA. Para o ligante FRA não foi possível demarcar a área deste pico. $\mathrm{O}$ desaparecimento de bandas de compostos aromáticos, provavelmente consumidos na reação de formação de novos aglomerados de asfaltenos, foi observado apenas para o ligante BRA. Para ambos ligantes se observou um aumento da banda do grupamento sulfóxido, os quais também são produtos da oxidação destes. O aumento do índice de condensação também foi observado apenas para o ligante BRA, sugerindo que mais compostos se agruparam para formar novas moléculas. Ao se observar a variação dos valores dos índices durante o envelhecimento clássico, notou-se que o ligante BRA apresenta uma maior variação na sua composição química que o ligante FRA, principalmente após ensaio RTFOT.

Sabe-se que as reações de oxidação e de formação de novas moléculas de maior massa molar são os principais eventos que podem acontecer durante o envelhecimento químico do ligante asfáltico. As reações de oxidação se traduzem principalmente pela formação de compostos como $\mathrm{C}=\mathrm{O}$ e $\mathrm{SO}_{2}$. Por meio da análise de FTIR, também se observou que, com o envelhecimento do ligante asfáltico, ocorre um aumento do $I_{\text {cond }}$ e diminuição do $I_{\text {aro }}$ devido à formação de macromoléculas ou aglomerados de moléculas, através da formação de ligações covalentes ou interações intermoleculares, como pontes de hidrogênio. Os aglomerados de asfaltenos ou asfaltenos assim formados são facilmente observados através de Cromatografia GPC ultra-rápida. 

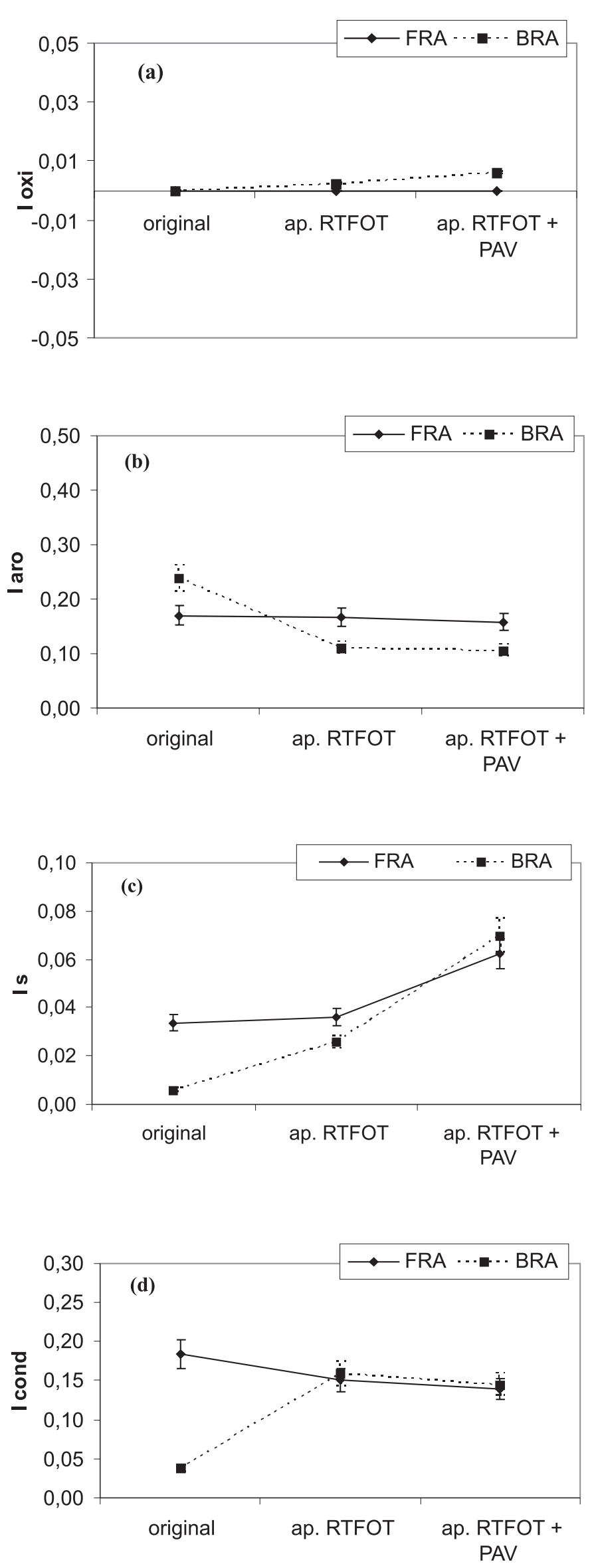

Figura 2: Índices de oxidação (a), aromáticos (b), sulfóxidos (c) e condensados (d) para os ligantes asfálticos FRA e BRA após etapas da simulação clássica

\subsubsection{Análise GPC}

As modificações estruturais em ambos ligantes, avaliadas por GPC, indicaram um caso atípico no que se refere ao número de gaussianas necessárias para se avaliar o cromatograma, ou seja, ao invés das três gaussianas usualmente utilizadas, foram utilizadas quatro. A Figura 3 apresenta um cromatograma de GPC com uma curva experimental e as 4 curvas gaussianas utilizadas na deconvolução desta. A região relativa à curva 1 é referente aos compostos de maior massa molar, ou seja, os aglomerados de micelas de asfaltenos; a da curva 2 é referente as micelas individuais de asfaltenos; a da curva 3 é referente as micelas de menor massa molar; e a da curva 4 é referente as moléculas isoladas, ou seja, óleos saturados e aromáticos, que constituem o meio intermicelar.

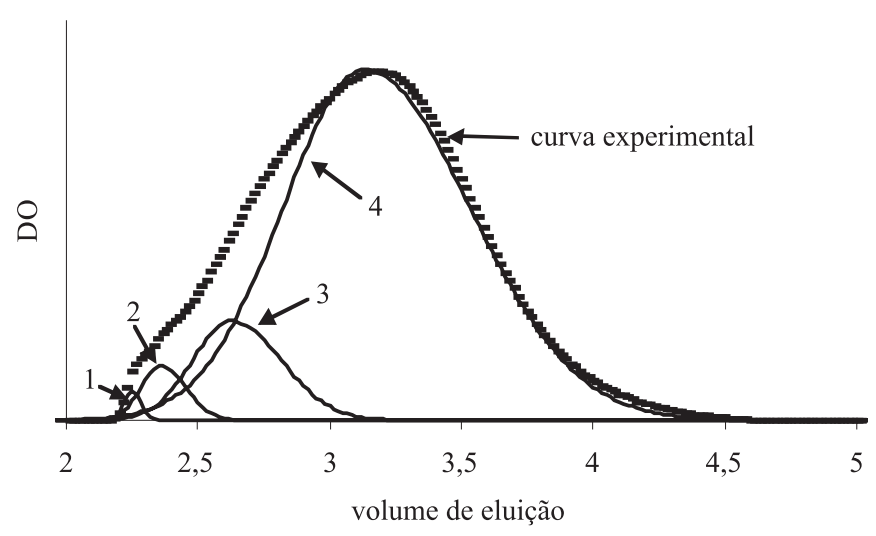

Figura 3: Curva experimental e curvas de deconvolução

A Figura 4 apresenta comparativamente as áreas referentes ao pico de interação, referente aos compostos de maior massa molar ou aglomerados de asfaltenos, para o ligante FRA e para o ligante BRA, determinadas após cada etapa da simulação clássica do envelhecimento. Observa-se que os ligantes, mesmo antes de serem submetidos ao envelhecimento, já apresentavam um pico de interação, sendo este mais intenso para o ligante FRA. Ambos ligantes apresentaram formação de aglomerados de asfaltenos com o envelhecimento, porém de maneira diferenciada. Enquanto que para o ligante FRA a formação de aglomerados foi sutil, para o ligante BRA foi acentuada após o ensaio de RTFOT, sendo então mais significativa após o ensaio de PAV. O ligante BRA, que apresentou maior variação na sua composição no sentido de formar compostos mais pesados, foi o ligante que apresentou visualmente maior envelhecimento após simulação RTFOT + PAV. Uma vez que ambos ligantes asfálticos pertencem à mesma classe de especificação, pode-se atribuir estas diferenças a variações na composição química ou à 
presença de metais que, segundo a literatura, podem ser catalisadores das reações que ocorrem durante o envelhecimento.

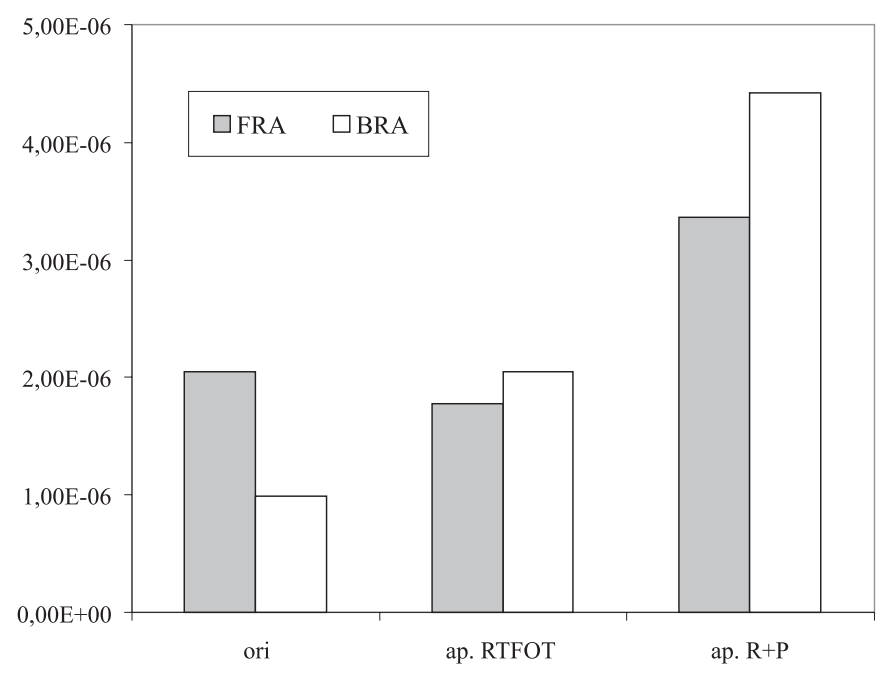

Figura 4: Área relativa da gaussiana 1 dos ligantes asfálticos FRA e BRA após etapas da simulação clássica

A fim de elucidar as diferenças na composição química dos ligantes asfálticos, eles foram analisados por Espectroscopia de Emissão Atômica por Plasma (ICP) para determinação de sua composição elementar. $\mathrm{O}$ procedimento foi realizado conforme artigo já publicado (Druon et al, 2000). A Tabela 2 apresenta os teores, em ppm, de Ni, V, S e P presentes nos ligantes FRA e BRA. Os resultados mostram que os ligantes possuem diferentes teores de metais, principalmente no que diz respeito ao teor de vanádio e enxofre. O ligante FRA é originalmente mais rico nestes elementos que o ligante BRA. Esses elementos podem servir de substratos para várias reações envolvidas no processo de envelhecimento. O vanádio comumente apresenta-se na forma de complexos de forfirinas de vanádio, que se comportam como agentes fotocatalisadores e de agregação molecular. Com sua estrutura em geometria plana, estes complexos podem se inserir entre outras moléculas ou ainda se fixar através de ligações $\mathrm{V}=\mathrm{O}$ (Glita, 1988). O enxofre pode se oxidar facilmente a dióxido de enxofre, $\mathrm{SO}_{2}$, ou comportar-se como um agente reticulante, como o faz na vulcanização de borrachas (Atkins e Jones, 1997, Herrington, 1995). Pela análise elementar, o ligante FRA seria um ligante asfáltico com alto potencial de envelhecimento sob incidência de radiação UV, no sentido de formar mais compostos oxigenados e moléculas de alta massa molar.
Tabela 2: Resultado análise elementar ICP dos ligantes FRA e BRA

\begin{tabular}{|l|c|c|}
\hline & FRA & BRA \\
\hline Ni (ppm) & 54,0 & 39,5 \\
\hline V (ppm) & 149,5 & 77,5 \\
\hline S (\%) & 3,5 & 1,8 \\
\hline P (ppm) & nd & nd \\
\hline
\end{tabular}

nd = não detetável

Como a simulação clássica de envelhecimento consiste em ensaios realizados em equipamentos fechados, sem incidência de luz, o ligante FRA não apresentou grande variação química e estrutural. Este ligante também parece ser originalmente mais envelhecido, pois é mais consistente ( $\downarrow$ Pen) e possui mais aglomerados de asfaltenos ( $\uparrow$ pico de interação), estando suas moléculas mais condensadas $\left(\uparrow I_{\text {cond }}\right)$, além de apresentar maior teor de $\mathrm{SO}_{2}\left(\uparrow \mathrm{I}_{\mathrm{s}}\right)$. Assim, o ligante FRA seria um ligante menos susceptível ao envelhecimento clássico, pois já estaria bastante envelhecido. O ligante BRA, originalmente menos envelhecido, possui menor consistência $(\downarrow$ Pen), menos aglomerados de asfaltenos ( $\downarrow$ pico de interação) e suas moléculas encontram-se menos condensadas $\left(\downarrow_{\text {cond }}\right)$. Tendo o ligante BRA menor teor de $\mathrm{SO}_{2}(\downarrow$ Is $)$ na origem, possui ainda substratos para envelhecer, podendo ser mais susceptível ao envelhecimento que o ligante FRA. O fato de o primeiro apresentar concentração inferior de elementos fotocatalíticos, como $\mathrm{V}$, pode impor um perfil bem particular frente a reações em presença de luz.

A análise reológica dos ligantes asfálticos permitiu calcular o índice de susceptibilidade termoelástica, ou seja o módulo elástico $\mathrm{E}_{\mathrm{T}}$. $\mathrm{O}$ valor de $\mathrm{E}_{\mathrm{T}}$ para o ligante BRA foi igual a 25.370, enquanto que para o FRA foi igual a 10.000, corroborando, então, a maior susceptibilidade ao envelhecimento do ligante BRA.

A avaliação dos ligantes asfálticos BRA e FRA por simulação clássica de envelhecimento mostrou claramente que estes, apesar de estarem enquadrados na mesma classe de especificação, seja esta brasileira ou européia, apresentaram perfis de envelhecimento diferenciados. Estas diferenças podem ser em conseqüência de sua diferente origem e processos de obtenção, o que implica em diferente teor de metais em sua composição química, bem como diferentes condições térmicas a que os ligantes asfálticos já foram submetidos. Sabe-se que, devido à complexidade destes materiais, provavelmente a diferença entre ambos ligantes não é conseqüência de uma causa 
isolada, e sim de um conjunto de fatores. Pode-se verificar, nas condições dos ensaios de simulação clássica realizados, que o ligante BRA foi mais susceptível ao envelhecimento que o ligante FRA, uma vez que apresentou maior oxidação e formação de aglomerados de asfaltenos após o envelhecimento. Considerando que o vanádio pode atuar como fotocatalisador e acentuar as diferenças no mecanismo de envelhecimento de ligantes asfálticos, os ligantes BRA e FRA foram também avaliados quanto ao processo de envelhecimento sob radiação UV.

\subsection{Estudo do "Efeito UV" sobre o} envelhecimento dos ligantes asfálticos

\subsubsection{Análise FTIR}

A Figura 5 apresenta os valores dos índices estruturais para os dois ligantes após o efeito UV, obtidos a partir dos espectros FTIR, calculados como descrito na subseção 2.3. Para melhor comparação também estão indicados nos gráficos os índices de cada ligante após RTFOT e após RTFOT+PAV.

Observa-se que os índices estruturais avaliados sofreram leves alterações após exposição dos ligantes a radiação UV. O ligante FRA após uma semana (168 h) sob efeito UV teve sua composição química alterada, mantendo-se estável daí até o fim da quinta semana. Este comportamento foi evidenciado pela variação dos índices $\mathrm{I}_{\text {oxi }}, \mathrm{I}_{\text {aro }}$ e $\mathrm{I}_{\mathrm{S}}$ após $168 \mathrm{~h}$ sob efeito UV se comparados com aqueles após RTFOT + PAV. O número de moléculas condensadas, expresso pelo índice $I_{\text {cond, }}$ não se alterou com o efeito UV. Acredita-se que a presença do elemento vanádio no ligante FRA seja responsável pelo envelhecimento deste sob radiação UV, uma vez que este elemento é um fotocatalisador e que, sob o efeito $\mathrm{T}$, o ligante manteve suas propriedades. Já o ligante BRA apresentou diferente evolução dos índices estruturais estudados. Apenas o $\mathrm{I}_{\text {oxi }}$ sofreu variação após uma semana (168 h) sob efeito UV, mantendo-se constante até a quinta semana $(840 \mathrm{~h})$ quando apresentou novo acréscimo. Os índices $\mathrm{I}_{\text {aro }}, \mathrm{I}_{\mathrm{S}} \mathrm{e} \mathrm{I}_{\text {cond }}$ não se alteraram após o efeito UV e apresentaram valores iguais àqueles após RTFOT + PAV. A ausência de um elemento fotocatalisador no ligante BRA pode ter provocado este comportamento. $\mathrm{O}$ efeito isolado da temperatura, efeito $T$, teve influência apenas nos índices $\mathrm{I}_{\mathrm{oxi}}$ e $\mathrm{I}_{\mathrm{s}}$, ou seja, na formação de produtos de oxidação. Ao se comparar estes índices com aqueles do efeito UV, se observou que a oxidação no ligante BRA pode ser ainda mais intensa após efeito T. A Figura 6 apresenta os índices de oxidação (a) e de sulfóxidos (b) do ligante BRA em função do tempo de exposição UV e também da temperatura.
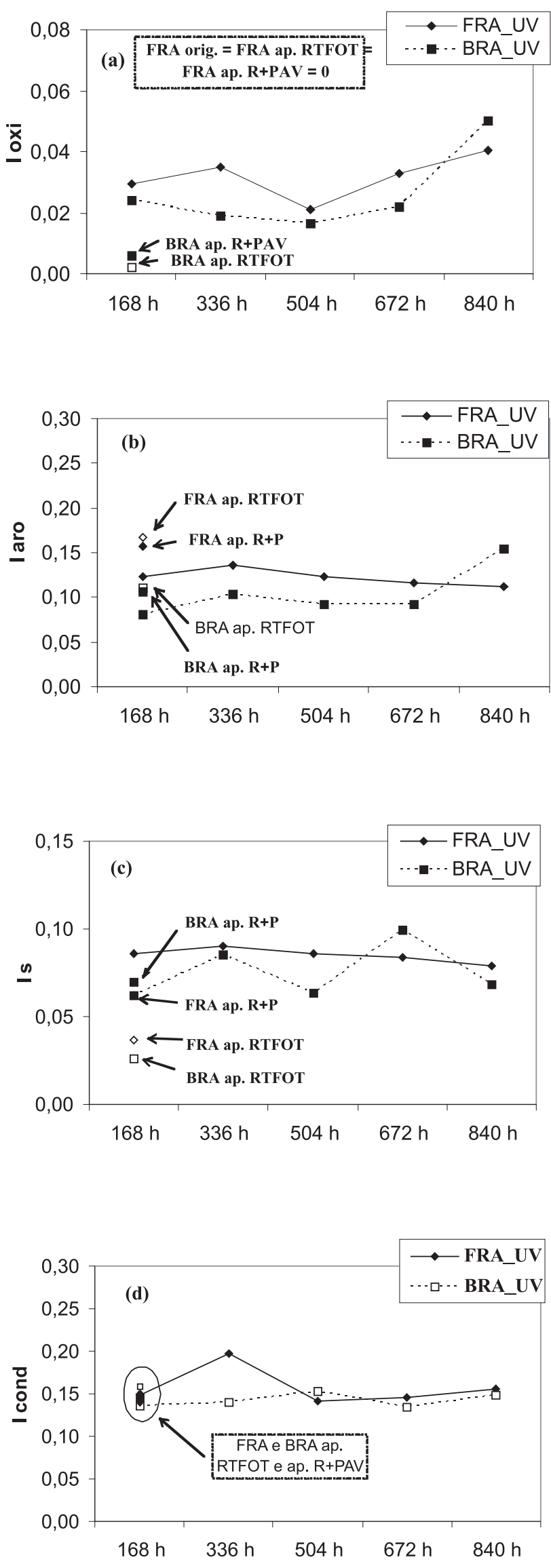

Figura 5: Índices de oxidação (a), aromáticos (b), sulfóxidos (c) e condensados (d) para os ligantes asfálticos FRA e BRA em função do tempo de exposição UV e da temperatura 

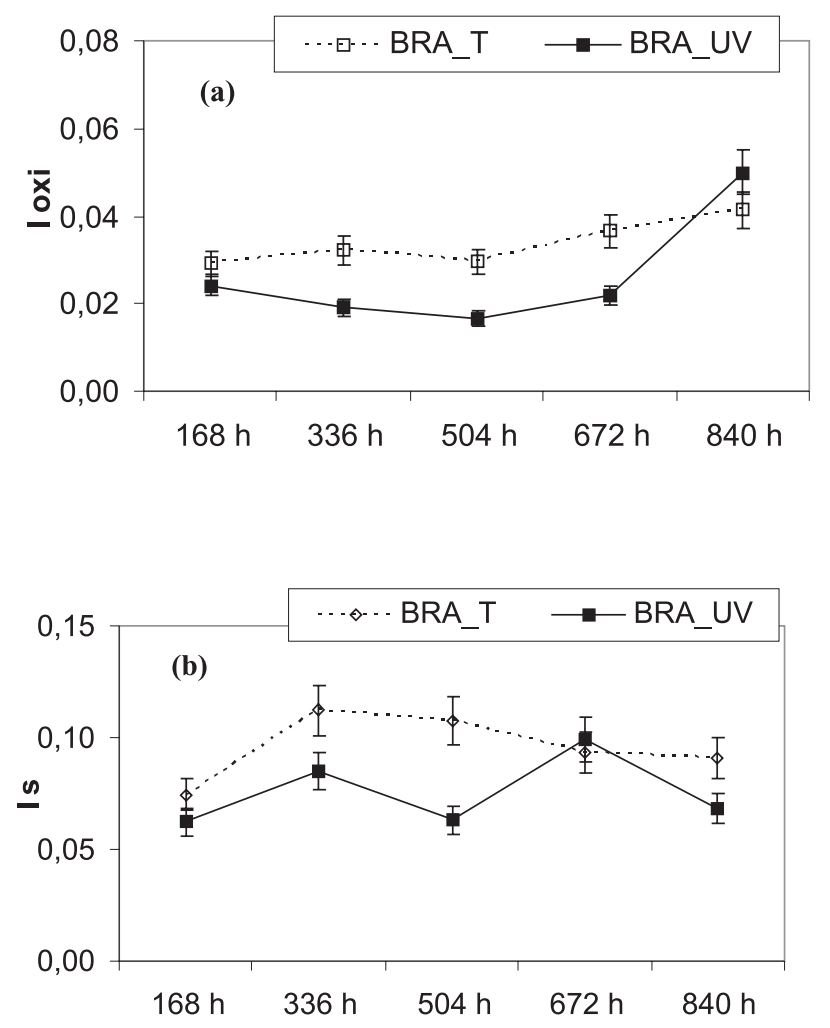

Figura 6: Índices de oxidação (a) e de sulfóxidos

(b) do ligante BRA em função do tempo de exposição UV e da temperatura

Uma explicação plausível para a maior oxidação do ligante BRA após o efeito $\mathrm{T}$ seria quanto à permeabilidade de oxigênio na amostra. Com o efeito UV, forma-se, via radical livre, uma película impermeável na superfície da amostra, impedindo o contato da porção subjacente com $\mathrm{O}_{2}$, protegendo-a da oxidação. Daí a variação da composição química ser mais significativa na primeira semana, pois com a formação da película impermeável, ocorre um retardo na taxa de envelhecimento ou até uma provável estabilização do meio. Sob incidência constante de radiação UV sobre a amostra, esta película altamente oxidada e rígida pode fissurar, romper, permitindo então a passagem de radiação UV e de $\mathrm{O}_{2}$ para camadas mais internas da amostra, envelhecendo-as. Esta hipótese explicaria o aumento do $\mathrm{I}_{\text {oxi }}$ do ligante BRA após a quinta semana de efeito UV.

\subsubsection{Análise GPC}

Para confirmar as considerações feitas, foi realizada análise de GPC ultra-rápido das amostras submetidas ao ensaio de envelhecimento. Assim como na subseção 3.1, estes resultados foram expressos pela área relativa da gaussiana 1, que é referente ao pico de interação, i.e., aos compostos de maior massa molar, os aglomerados de micelas de asfaltenos. Observa-se, na Figura 7, a evolução da área do pico de interação em função do tempo de exposição UV e da temperatura.
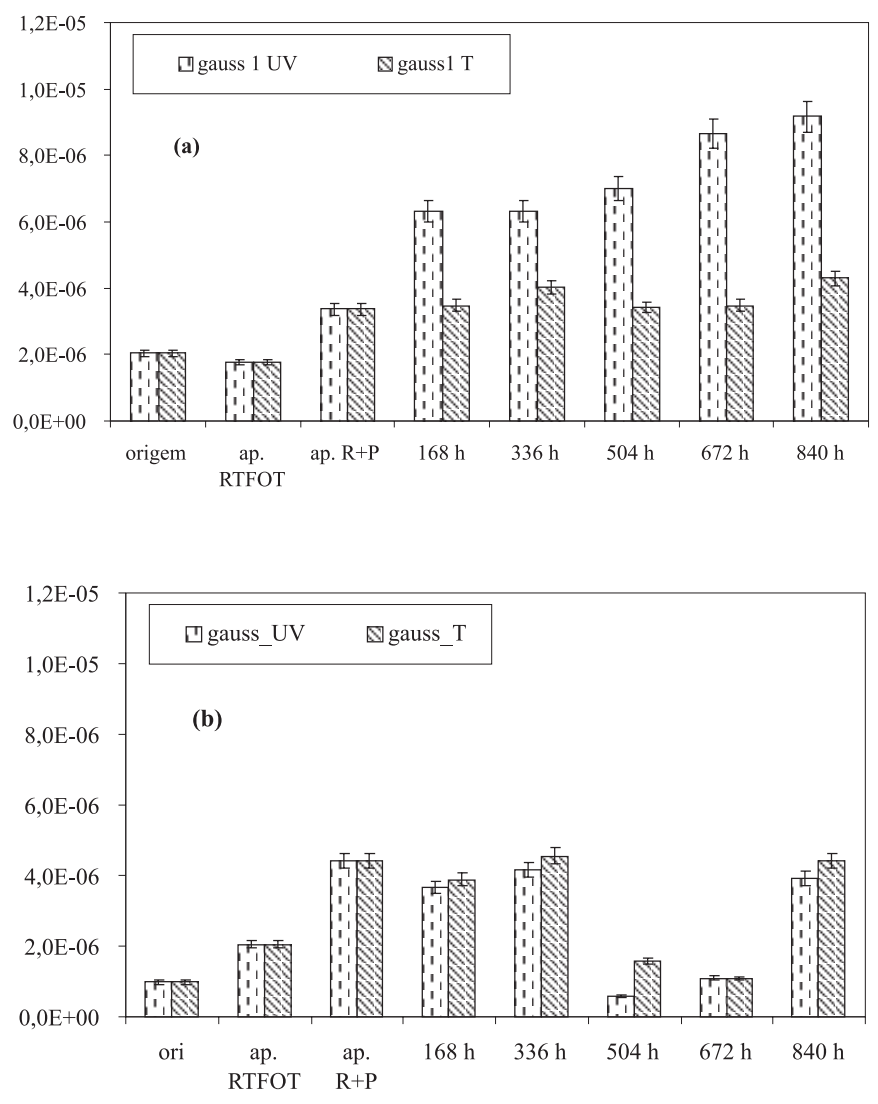

Figura 7: Área relativa da gaussiana 1 dos ligantes asfálticos FRA (a) e BRA (b) em função do tempo de exposição UV e da temperatura

Observou-se que a evolução da área do pico de interação foi diferente conforme o tipo de ligante asfáltico e tratamento aplicado à amostra. Para o ligante BRA, o envelhecimento $\mathrm{UV}$ e a $60^{\circ} \mathrm{C}$ foi muito parecido, não havendo formação de aglomerados, enquanto que para o ligante FRA não houve formação de aglomerados apenas após exposição a $60^{\circ} \mathrm{C}$, i.e., não houve envelhecimento provocado pelo calor. Porém após uma semana sob efeito UV observou-se uma produção significativa de aglomerados de asfaltenos, a qual tornou-se maior após 4 semanas, o que confirmou o efeito fotocatalisador do $\mathrm{V}$, abundante neste ligante.

Para o ligante BRA observou-se uma diminuição do pico de interação em 3 e 4 semanas de exposição. Pode-se também observar na Figura $7 \mathrm{~b}$ que este ligante possui uma suave tendência à maior formação de aglomerados sob efeito T que sob efeito UV, demonstrado pelas áreas dos picos serem levemente superiores em todos os períodos de exposição a temperatura. A diminuição do pico de interação, i.e., do teor de aglomerados em 3 e 4 semanas de envelhecimento do ligante BRA poderia estar relacionada com um rearranjo molecular do meio, ou seja, grandes aglomerados de micelas se rearranjariam fisicamente em aglomerados menores, uma vez que este ligante não possuiria mais agente agregador $\mathrm{V}$ 
disponível, atingindo a saturação de seus substratos para as reações de envelhecimento. Com o rearranjo molecular, ocorre um desequilíbrio do sistema coloidal asfáltico, que se pode observar pela variação do índice de instabilidade coloidal, Ic, calculado a partir das frações químicas SARA do ligante asfáltico.
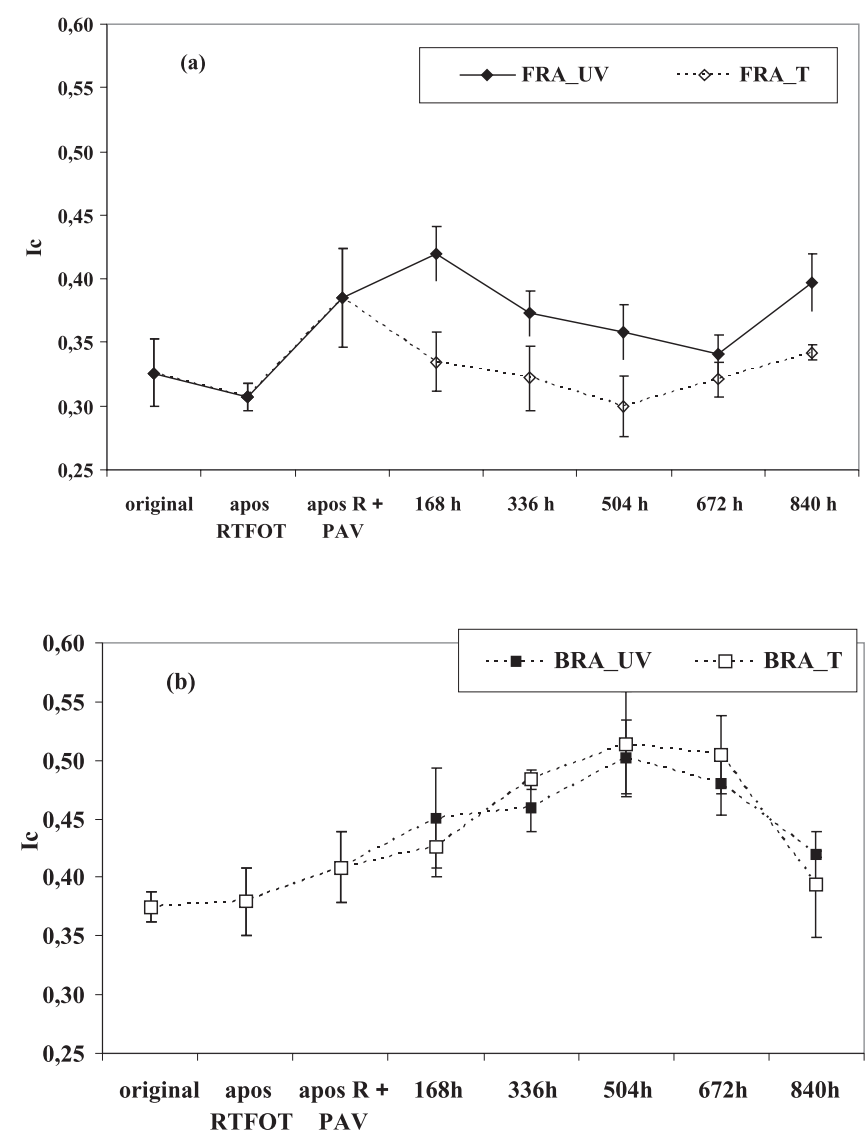

Figura 8: Evolução do Ic dos ligantes asfálticos FRA (a) e BRA (b) em função do tempo de exposição UV e da temperatura

A Figura 8 mostra a evolução do índice Ic, após efeito UV e T, para os dois ligantes asfálticos. A variação do Ic foi coerente com a evolução do pico de interação observada por GPC ultra-rápido, ou seja, o ligante FRA apresentou uma evolução contínua após RTFOT + PAV, diferenciada para efeito $\mathrm{T}$ e efeito UV, enquanto o ligante BRA apresentou um aumento do Ic em 3 e 4 semanas de exposição, seja por efeito T ou efeito UV.

Para melhor investigar a modificação da superfície da amostra exposta a radiação UV, foram confeccionados filmes finos de ligante asfáltico, com aproximadamente $700 \mu \mathrm{m}$ de espessura, preparados conforme 2.1, os quais foram expostos durante 5, 24, $48,72,96,192$ e 339 horas ao efeito UV e efeito T, sendo em seguida analisados por espectroscopia de FTIR e por Cromatografia IATROSCAN. A Figura 9 mostra a variação dos índices $\mathrm{I}_{\text {oxi }}$ e $\mathrm{I}_{\text {cond }}$ do ligante BRA em função do tempo de exposição ao efeito UV e ao efeito T. Após o efeito UV a superfície foi altamente oxidada com formação de moléculas bastante condensadas. Após efeito T a superfície sofreu leve oxidação e o número de moléculas condensadas foi constante. Tal comportamento também foi observado para o ligante FRA, não se notando diferenças na composição química da camada superficial formada com a espessura adotada. A formação de grupamentos carbonila ou o $I_{\text {oxi }}$ não variou a partir de um determinado período de exposição UV, atingindo um patamar em 50 horas de exposição. Com relação à condensação de moléculas $\left(\mathrm{I}_{\text {cond }}\right)$, observou-se que ocorre uma diminuição da intensidade destas bandas com o tempo, sendo que, mais uma vez, a partir de 50 horas de exposição ocorre uma estabilização deste. Sendo assim, pode-se dizer que as reações de oxidação sob radiação UV na superfície dos ligantes asfálticos ocorreram em tempos mais curtos e mais intensamente, sendo que em 50 horas de exposição ocorreu um desaparecimento significativo das espécies reativas envolvidas. Neste ponto se observou os $\mathrm{I}_{\text {oxi }}$ e $\mathrm{I}_{\mathrm{s}}$ máximos e os $\mathrm{I}_{\text {aro }}$ e $\mathrm{I}_{\text {cond }}$ mínimos o que mostrou a ocorrência de alta oxidação dos dois ligantes. Todavia, levando-se em consideração a dispersão dos pontos neste período, é necessário o estudo destas evoluções nas primeiras horas de exposição UV.
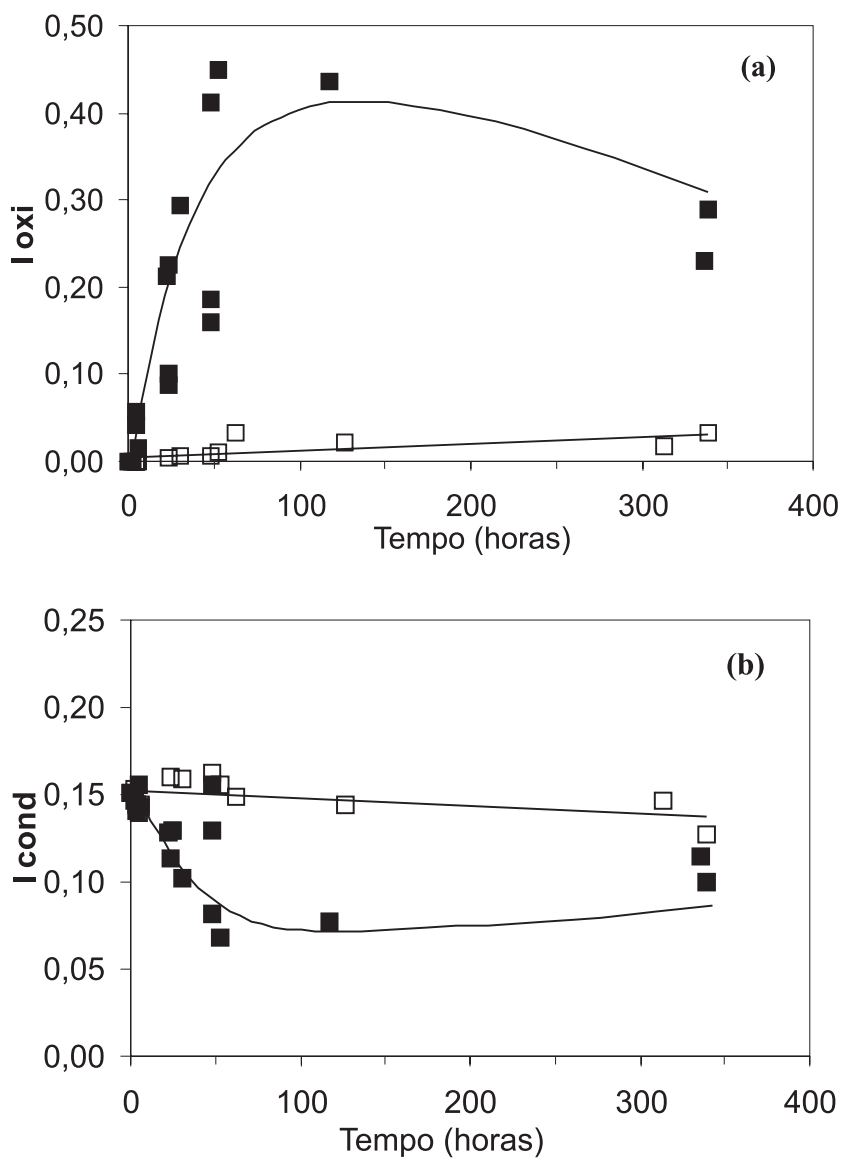

Figura 9: Evolução dos índices de oxidação (a) e de condensados (b) do ligante BRA em função do tempo de exposição UV ( $\square)$ e T ( $\square$ ) de um filme fino 
A Figura 10 apresenta a variação do Ic em função do tempo de exposição para o ligante BRA envelhecido sob filme fino. Observa-se um máximo no valor de Ic para aproximadamente 50 horas de exposição UV, confirmando os resultados de FTIR, o que mostra a alta instabilidade coloidal do ligante asfáltico neste período.

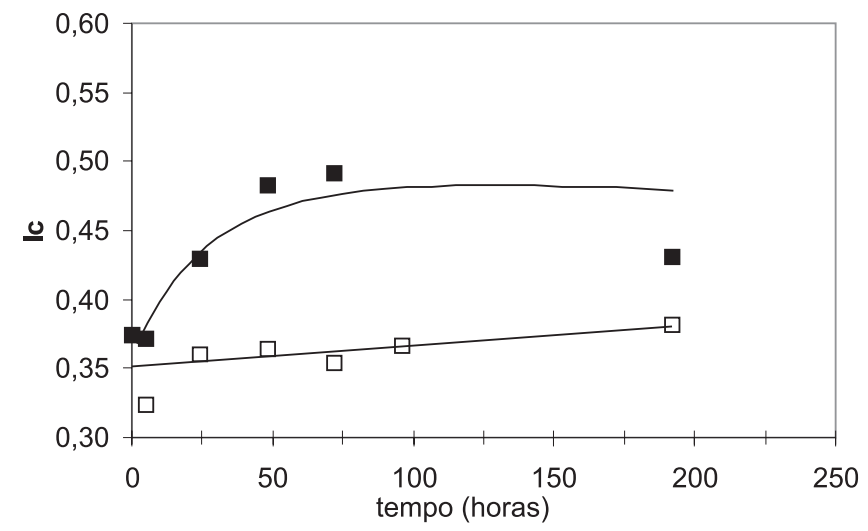

Figura 10: Evolução de Ic do ligante BRA em função do tempo de exposição

UV ( $\square)$ e T ( $\square)$ sobre um filme fino

Assim como na simulação clássica de envelhecimento, observou-se que ambos ligantes asfálticos em estudo apresentaram, no ensaio proposto, mecanismos de envelhecimento bastante distintos.

No ligante FRA, rico em vanádio, após exposição ao efeito UV, houve a formação de uma película na superfície da amostra bastante oxidada e rica em aglomerados de asfaltenos. Esta película atuou como uma barreira prevenindo o envelhecimento da camada subjacente. Esta camada formou-se quase que integralmente na primeira semana, variando muito pouco até a quinta semana de efeito UV. Após o efeito T, o mesmo ligante não sofreu envelhecimento, provavelmente pelo efeito combinado da escassez de substratos e da ausência de luz.

No ligante BRA, após exposição ao efeito UV, também houve a formação de uma película na superfície da amostra bastante oxidada, porém pobre em aglomerados de asfaltenos. Supõe-se que esta película era mais frágil que aquela do ligante FRA, pois na terceira e quarta semana após o efeito UV ocorreu um rearranjo molecular do meio ocorrendo uma alta instabilidade do sistema. As possíveis causas para este fenômeno foram atribuídas à ausência de um agente agregador (V) capaz de 'organizar' esta camada, deixando-a mais frágil. Foi observada visualmente a presença de fissuras na superfície exposta deste ligante, o que pode ser relacionado ao aumento da oxidação global (Ioxi) na última semana, devido à penetração de $\mathrm{O}_{2}$ no seio da amostra. Com o efeito T o comportamento foi muito semelhante, salvo que a penetrabilidade de $\mathrm{O}_{2}$ na amostra foi maior e o envelhecimento global observado levemente superior.

\section{CONCLUSÕES}

Com relação ao envelhecimento dos ligantes asfálticos pela radiação UV verifica-se que esta influencia no mecanismo de envelhecimento destes de maneira diferente. Para o ligante FRA ocorreu maior formação de aglomerados de asfaltenos após exposição UV. Para o ligante BRA, a radiação UV não teve efeito e, após 3 a 4 semanas de exposição, observouse um rearranjo molecular do meio. Tais diferenças podem ser atribuídas às diferentes origens destes dois ligantes asfálticos, o que se traduz principalmente por diferentes teores de vanádio, que funciona como fotocatalisador de reações iniciadas por UV. $\mathrm{O}$ envelhecimento UV foi associado à formação de uma camada impermeável na superfície da amostra, que impede a penetração de $\mathrm{O}_{2}$ na amostra, inibindo menos o envelhecimento global do ligante exposto à radiação UV que quando sob efeito somente do calor.

O envelhecimento de ligantes asfálticos devido a radiação UV não está previsto na seqüência de ensaios na simulação clássica usualmente utilizada em laboratório. Estes ensaios são realizados em equipamentos fechados, na ausência de luz, e portanto na ausência de radiação UV, não prevendo importantes reações iniciadas por esta que ocorrem no envelhecimento de ligantes asfálticos em serviço, como se procurou avaliar neste estudo.

\section{AGRADECIMENTOS}

Os autores deste trabalho agradecem a Ipiranga Asfaltos S/A (IASA) e ao Laboratoire Central des Ponts et Chaussées (LCPC) pelo fornecimento de amostras e a CAPES e CNPq pelo apoio financeiro.

\section{REFERÊNCIAS BIBLIOGRÁFICAS}

ABNT e IBP (1971) MB-164 - Determinação da Penetração de Materiais Betuminosos. Rio de Janeiro, 3 p.

ABNT e IBP (1972) MB-164 - Determinação do Ponto de Amolecimento de Materiais Betuminosos (Método do anel e bola), Rio de Janeiro, 3 p.

Atkins, P. e Jones, L. (1997) Chemistry - Molecules, matter, and Change (3a Ed.). Freeman and Company, New York, USA.

Bahia H., Hanson D., Zeng M., Zhai H., Khatri M. e Anderson R. (2001) Characterization of Modified Asphalt Binders in Superpave Mix Design - NCHRP Report 459. National Academic Press, Washington, USA.

Barth E.J. (1962) Asphalt. Gordon and Breach, New York. 
Carreau J-P, Bousmina M., Bonniot F. (2000) The Viscoelastic Properties of Polymer-Modified Asphalts. The Canadian Journal of Chemical Engineering, v. 78, p. 495-503.

Druon M., Mondon V. e Touzé P. (2000) Introdution des produits organiques en spectroscopie ICP-AES par simple mise en emulsion. Aplication au dosage de $\mathrm{Ni}$ et $\mathrm{V}$ dans le bitume. Bulletin Laboratoire des Ponts et Chaussées, v. 225, n. 13.

Durrieu, F., Lamontagne, J., Mouillet, V., Planche J-P (2004) Differentiated Chemical Evolutions of Phases in Polymer Modified Bitumen during their Ageing : an Infrared Microspectrometric Study. In : Proceeding of 3rd Eurasphalt \& Eurobitume Congress, Viena, Austria, paper 86.

Farcas, F. (1996) Étude d'une méthode de simulation du vieillissement des bitumes sur route. Thèse de doctorat de l'Université Pierre-et-Marie Curie (Paris VI).

Glita S. (1988) Contribution à l'étude physico-chimique des bitumes. Thèse de doctorat a la Faculté des Sciences et Techniques de l'Université du Havre.

Herrington P.R. (1995) Thermal decomposition of asphalt sulfoxides. Fuel, v. 74, n. 8, p. 1232-1235.

Herrington, P. e Ball, G. (1996) Temperature dependence of asphalt oxidation mechanism. Fuel, v. 75, n. 9, p. 1129-1131.

Ishai I. (1984) Quantitative characterization and evaluation of bitumen parameter related to the durability of asphaltic pavements. ENPC, CERMES, Paris, p. 122.

Knotnerus (1973) La longévité des bitumes mesurée par absorption d'oxygène. Bulletin Laboratoire des Ponts et Chaussées, v. 68, n. 125.

Lamontagne J., Kister J. , Durrieu F., Planche J-P., Mouillet V. (2001) New investigations on ageing of polymer modified asphalts by infrared microspectry imaging. Anais da 52st Pittsburgh Conference, New-Orleans, USA.

Leite L.F.M. e Camillo M.C.F. (1988) Caracterização de Cimentos Asfálticos através da Técnica de HP-GPC. Anais do $9^{\circ}$ Encontro de Asfalto, p. 231-260.

Migliori F., Corté J-F. (1998) Comparative Study of RTFOT and PAV Ageing Simulation Laboratory Tests. Transportation Research Record, 1638, p. 56-63.

Moschopedis S.E., Speicht J.G. (1975) Fuel, v. 51, n. 210.

Norma Européia NF EN 12591 (1999) Bitumes et liants bitumineux, Spécifications des bitumes routiers.

Pieri, N. (1994) Etude du vieillissement simulé et in situ des bitumes routiers par IRTF et Fluorescence UV en mode Excitation-Emission Synchrones. Thèse de l'Université d'AixMarseille III, 214 p.

Traxler R.N. e Scrivner F.H. (1971) American Chemical Society, Division Petroleum Chemistry, Preprints, 16, 102.

Whiteoak, D. (1990) Shell Bitumen Handbook. Inglaterra, Shell.

Letícia Socal da Silva (00108380@ufrgs.br)

Wright P.H. e Paquette R. J. (1968) Hardening of asphalt in hot bituminous mixes during the hauling process. Highway research record, v. 19, n. 132, p. 10.

Maria Madalena de Camargo Forte (mmcforte@ufrgs.br)

Philippe Bartolomeo (bartolomeo@1cpc.fr)

Fabienne Farcas (farcas@ufrgs.br)

Françoise Durrieu (francoise.durrieu@lcpc.fr) 